\title{
Professional Training to Develop Content-Based Instruction in Higher Education
}

\section{Michael Sagliano, Timothy Stewart, and Julie Sagliano}

Many TESL professionals have not had training specifically in content-based instruction (CBI) methodology. The lack of professional training in $C B I$ is increasingly problematic as the number of programs adopting some content-based methodology continues to rise. One obvious response to this gap in pedagogical training could be for institutions engaging in CBI to create their own professional orientation programs for experienced faculty members. This article describes one such response at a Japanese university. Drawing on our four years' experience in developing a specific CBI teacher training program, we suggest a number of training points that could be used by teacher trainers to help college faculty to overcome the major hurdles encountered in implementing a CBI approach in higher education.

This article highlights broad issues in teacher training and offers specific guidelines for training in adjunct (linked), sheltered, and English for Academic Purposes (EAP) content-based university-level programs in order to augment contemporary insights about orienting teachers in content-based programs. First a brief overview is presented of the recent state of professional faculty development in higher education. Then common elements of teacher training for content-based programs that have been gleaned from the literature are summarized. Next we describe what we believe to be key training points for content-based instruction (CBI). In this main section some of the commonly recognized professional training factors are merged with others previously disregarded or largely downplayed: meeting the personal needs of faculty prior to addressing professional concerns; changing the naturally autonomous tendency of college faculty to practices inspiring greater commitment to an interactive and cooperative teaching culture; actively involving participants in their own training; and maintaining a rich and extensive inservice program. The broad aspects of socialization that should be addressed in the training of new faculty in a content-based setting are stressed: socializing them to a new institutional, academic, and teaching culture, as well as to different classroom approaches. Finally, some of the ongoing challenges related to teacher development that have become evident in our training program are outlined. 
Indeed, "content-based instruction is a growing enterprise [as] ... interest in integrated language and content programs has increased dramatically" (Snow \& Brinton, 1997, p. xi). Yet it appears that many TESL teacher preparation programs have not kept up with this trend by offering separate courses on integrated content and language instruction (Peterson, 1997). Of the institutions that do offer education courses in $\mathrm{CBI}$, second-language instruction in elementary schools and high schools is the focus rather than instruction at the postsecondary level or in foreign language contexts. In light of this situation, teacher trainers might well wonder what is the most effective and expeditious way to proceed in preparing college faculty for content-based teaching.

Until recently little research into the induction of new staff into higher education has been conducted, so the literature about this topic is almost nonexistent (Dunkin, 1990). Similarly, according to Kaufman and Brooks (1996), "Little documentation exists about innovative ventures within teacher education programs that are designed to prepare teachers for interdisciplinary collaboration and integration of language and content" (p. 233). When educators do collaborate, there is certainly a potential for conflict. At the beginning of teaching partnerships, an obvious issue of immediate concern is the relationship between the instructors. "The best way to improve this relationship is to communicate, and communication is best fostered through preservice and in-service training" (Master, 1992, p. 80).

Drawing from our experiences during four years of developing a training program for $\mathrm{CBI}$, we suggest five major points for effective faculty training. We have found that a professional orientation program can be helpful to a faculty that lacks previous pedagogical training in CBI. Descriptions of our pre- and inservice training programs are used throughout this article to illustrate how the training points we are suggesting for orienting teachers in $\mathrm{CBI}$ have been successfully used in one postsecondary context.

\section{An Overview of Professional Training Programs in Higher Education}

Overall, the professional development of new college faculty has been haphazard in past years. Because little evidence exists that faculty development programs are successful over the long run, most institutions of higher education remain unconvinced of the need to sustain such programs (Boice, 1992). There are exceptions, of course, and some high profile institutions in higher education do offer faculty development assistance. For example, major United States universities such as Stanford, MIT, and Columbia have recently made the improvement of teaching a priority. More and more colleges are establishing faculty development offices that provide their instructional staff 
with opportunities to consult specialists in pedagogy (Hativa, 1995; Smith, 1995).

Fink (1992), in his study of five types of orientation programs for incoming faculty at US colleges and universities, found that new faculty could not be expected to know everything necessary to be effective members of an institution. He strongly advocates that institutions offer orientation programs, promoted and supported by administration, that encourage the professional development of faculty members. Boice $(1992,1995)$ agrees and argues convincingly that to be successful in the professoriate, faculty members need serious programs in both research/writing and teaching in order to maintain an essential balance of improved mastery in these two primary work areas of academicians. He points out, however, that "most faculty development programs have been narrowly conceived" and usually are staged "in brief, episodic fashion" $(1992$, p. 8).

\section{Preservice Training in Content-Based Methodology: Past Efforts and Key Elements}

In the field of content-based language education, preservice and inservice training of language and content teachers for different teaching situations have been urged or developed (Brinton, Crandall, Kaufman, Snow, \& Stoller, 1998; Brinton, Snow, \& Wesche, 1989; Gomez, 1995; Hess \& Ghawi, 1997; Hones \& Gee, 1993/1994; Jameson, 1996; Kaufman, 1997; Kaufman \& Brooks, 1996; Master, 1992; Peterson, 1997; Short, 1991b; Snow, 1992, 1997; Snow \& Kamhi-Stein, 1996; Tricamo \& Snow, 1995). These training programs were designed to achieve a wide range of purposes including orienting and socializing new teachers to an institution and its policies, a specific teaching situation, a particular curriculum, and expectations about research.

The literature on actual or recommended preservice teaching workshops in second-language, content-based contexts describes some elements that contribute to successful preservice programs at the postsecondary level. These could be incorporated into any CBI training venture.

For preservice teaching workshops in second-language, content-based contexts to be effective, they need to be strongly supported by the administration of an institution (Brinton et al., 1989; Short, 1991b). If the program incorporates innovative approaches such as active learning, "senior academic officials must create a climate for improving instruction" (Bonwell \& Eison, 1991, p. 73). The creation of such an environment is often started in teaching workshops offered by training facilitators (Gomez, 1995; Master, 1992; Short, 1991b, 1994). In many such workshops teachers are organized into teams to foster cooperative relationships (Brinton et al., 1989; Chamot \& O'Malley, 1994; Master, 1992). Facilitators generally lead groups of teachers by describing desired teaching approaches and demonstrating classroom 
techniques (Gomez, 1995). Instead of merely listening passively to theoretical monologues, it is necessary to have groups of participants actively engaged in the workshops by discussing and designing activities and class materials, and by presenting lessons (Master, 1992; Short, 1991b). After the sessions the trainers should give the teams feedback. All the professional development programs surveyed for this article vary regarding timing, length, and the question of mandatory versus voluntary participation by newly appointed faculty.

The content-based training program we have been involved in conducting for EFL and discipline-area specialists combines many of these same elements, but adds others directly related to teacher socialization. We have discovered that an academic culture can be created through a professional orientation program that tackles challenges of teacher socialization, for example, alleviating culture shock, familiarizing faculty with unfamiliar pedagogical approaches, and developing a spirit of collaboration. In order to deal effectively with such professional development needs, we propose the following training points as being important elements for training in CBI: orientation to a new community; socialization to a new institution; introduction to preferred pedagogies; socialization to cooperative teaching arrangements; and inservice training (see appendix A for an overview of the preservice training schedule followed by our college in 1998).

\section{The Setting}

The training program reviewed in this article is under development at a unique Japanese university where pairs of EFL and discipline-specific college faculty team-teach credit-bearing content courses. Miyazaki International College (MIC) is a small, four-year liberal arts institution located in southwestern Japan. MIC's mission is to develop bilingual (English/Japanese) students who possess critical thinking skills.

Teams of language specialists and discipline specialists teach first- and second-year classes consisting of 10-24 students. As an integral part of the college's mission, the faculty use active learning approaches in teaching. In a typical semester most EFL and discipline-specific faculty are assigned to two team-taught courses. After co-planning the syllabus and lessons, they teach together for six hours per week during a 15-week period. Content concepts, language, and critical thinking skills are presented in an integrated manner. With the exception of Japanese expression courses, faculty use English as the instructional language.

Ninety percent of the faculty are non-Japanese, which contrasts sharply with the fewer than $2 \%$ for all other Japanese colleges and universities (Otsubo, 1995). There are currently 38 team-teaching faculty, of whom 27 come from North America, 4 from Japan, 4 from other Asian countries, 2 
from Europe, and 1 from Africa. The gender ratio of faculty is $63 \%$ male to $37 \%$ female; ages range from approximately 25 to 55 .

Teams must teach a student body whose educational background creates challenges for active learning in English. Japanese high school students have limited experience in oral/aural English skills and little exposure to academic English. Their secondary education has been overwhelmingly passive in nature. On entering MIC the students' English proficiencies range from low-intermediate to advanced.

New teachers are initially at a disadvantage in dealing with this new institutional and cultural environment. Most EFL and discipline-specific teachers lack team-teaching experience; some are unfamiliar with active learning approaches and content-based language teaching; about half have never taught in Japan before. In addition, a number of the discipline-specific teachers in particular have not taken courses in teaching methods, nor have they taught full classes of students with limited English skills and have only taught using a lecture-style format.

In response to these realities, the theory and practice of content-based teaching must be first understood, and then reshaped to a fully integrated team-teaching approach that will meet the needs of Japanese learners. Success of the program depends on socializing teachers to this new academic, institutional, and cultural environment.

\section{Training Point \#1: Orientation to a New Site}

Aim: Socialize faculty to a new setting and attend to their personal needs. Newly hired faculty have commented that it is crucial after arriving at a new teaching site to be provided with the necessary "breathing space to settle into offices and living arrangements, get personal affairs in order" and have "some scheduled personal time ... to take care of moving-in chores" (Sagliano, 1996). Understandably, the personal needs of faculty must be satisfied to a great degree before they can devote their attention, energy, and commitment to professional matters.

A common concern for many faculty immediately on their arrival is computer availability. Many teachers are anxious to read their e-mail and use their computers. On our campus some new colleagues quickly feel a need to learn more computer-assisted research and teaching applications as our network makes these resources available to them, sometimes for the first time. Naturally this requires training by technical personnel, as well as educators familiar with the use of the computer in teaching. After completing a needs assessment a few days after their arrival, new faculty receive appropriate training in computer use. Four two-hour sessions are held during the preservice training program, including a preservice workshop on the use of computers as an active learning tool by collaborative teams. 
This is an example of one of the most immediate needs felt by newly arrived faculty. Encountering and quickly adapting to a new society and culture are added burdens for foreign faculty. For professional training facilitators, these should be the primary concerns for initial teacher socialization. To address the immediate needs of our new faculty, we begin with a personal orientation through e-mail, fax, and telephone communications that starts at the time they are hired. Assistance with moving arrangements is provided, and full descriptions of residential areas are given so that new personnel can select a suitable housing arrangement prior to their arrival. On their arrival, personal orientation concludes with two weeks of individualized attention in areas such as banking, schools, shopping, medical care, and transportation provided by experienced faculty to get newly arrived colleagues and their families settled into unfamiliar communities. Also, this is when computer needs are assessed and the first computer session is held (Computer session \#1). When everyone's mind and will are focused on professional growth, an appropriate period of professional preservice training can proceed in earnest.

\section{Training Point \#2: Introduction to a New Acadernic Culture}

Aim: Socialize faculty to a new academic culture (i.e., institution, mission, learning theory, and teaching approaches). "Learning a new campus culture requires adjustment, even for experienced faculty" (Boice, 1992, p. 220). At our college, for example, content and language teachers alike have to become accustomed to a teaching situation that, to varying degrees, is different from their previous experiences, no matter whether they are Japanese or foreign teachers. For instance, native Japanese faculty members might have completely different expectations of what it means to be a professor in a college in Japan; therefore, they could become disoriented when confronted with an institution that is not compatible with their notion of traditional Japanese educational programs. Some foreign teachers might expect to continue to instruct in their own time-honored teaching styles brought from their home countries and, therefore, could resent being asked to explore new modes of planning, instructing, and thinking about teaching.

After the conclusion of personal orientation at our college, entering faculty are required to participate in several days of preservice workshops before the start of the first semester. Our college's preservice program is a type that Fink (1992) has termed "Presemester Mandatory" (p. 42). The paramount objective of our professional orientation program is to present the institution's mission in integrating academic content and English language instruction by using active and cooperative learning approaches. Once the personal needs and interests of faculty have been dealt with, preservice facilitators devote an early session of orientation to administrative matters by outlining the college mission, curriculum, and academic policies. The inten- 
tion of this session is to inform, not to overwhelm colleagues with administrative details. To give new faculty a deeper sense of the college's mission, the president shares his vision for a new institution in Japanese higher education that emphasizes the promotion of critical thinking and the use of active learning strategies in the classroom. Next, new faculty members are provided with a brief general outline of the curriculum and academic policies.

Meeting the immediate campus needs of faculty is also an important part of welcoming colleagues to an unfamiliar institution. We explain where to find resources they need, and we introduce knowledgeable staff to whom they should direct particular types of queries. New colleagues are familiarized with our campus facilities on a resource tour conducted by experienced peers. Finally, in an attempt to head off the inevitable frustrations of cross-cultural misunderstandings, new faculty are given a primer in Japanese etiquette that concentrates on appropriate and effective approaches for getting things done in Japan.

\section{Training Point \#3: Introduction to a New Pedagogy}

Aim: Familiarize faculty to content-based teaching by having them actively engage in it. Adequately preparing EFL and content teachers for effective CBI is the primary challenge in teacher training for our institution and potentially for others as well. Many practicing ESL/EFL teachers have had no previous training in content-based methodology because it has not been a standard part of TESL programs (Kaufman, 1997; Kaufman \& Brooks, 1996; Peterson, 1997; Short, 1991a). "CBI requires an adjustment on the part of the ESL teacher," according to Master (1992), "it raises questions about teacher training for new teachers and teacher development for those who have been teaching ESL for some time" (p. 77). Brinton et al. (1989) claim that successful implementation of the adjunct model for CBI requires close coordination among teachers, staff, and administrators.

For new institutions intent on offering nontraditional instructional alternatives, the challenges are greatly magnified, particularly in EFL contexts. If an institution is attempting something innovative such as replacing the lecture format with active learning techniques, it must create an improved environment for instruction by altering the "social and cultural mores defining the role of teaching there" (Bonwell \& Eison, 1991, p. 73). In reference to the shift from teacher-centered to learner-centered approaches, Meyers and Jones (1993) conclude: "The simple fact is that changing one's style of teaching and modifying settled methods is at best a difficult task" (p. 158). Yet both active and cooperative learning approaches require extensive teacher preparation and commitment. Obviously energetic leadership and support by administrators is vital to the successful promotion of these approaches in any institution. Together with this, some specific strategies for teachers can 
be urged, for example, encouraging risk-taking in the classroom and introducing different teaching approaches to meet various student learning styles. Also, administrators should outline institutional expectations clearly and reward teachers who are committed to teaching as the prime goal of the institution (Bonwell \& Eison, 1991; Johns, 1997; Smith, 1995).

At our institution, preparing EFL and content teachers for effective discipline- and content-based instruction and for collaborative team-teaching are two major teacher socialization tasks. This type of team-teaching requires extensive teacher preparation and commitment. Our experience confirms findings that training in CBI methodology is lacking in many TESL programs. Similarly, content specialists have had little or no experience teaching LEP (limited English proficiency) students. Thus, as Snow asserts, few content teachers understand the backgrounds and needs of second-language learners (Brinton et al., 1998). In addition, it is true that "discipline specific faculty are not particularly interested in changing their approaches to teaching ... [as] very little in their educational histories encourages them to question [traditional teaching] practices" (Johns, 1997, pp. 71-72). To support this viewpoint, one recent study plainly illustrates that for discipline-specific instructors, "lectures are 'the substance of the course" (Flowerdew \& Miller, 1996, p. 124). When they begin to teach classes of LEP students, however, many find their teaching methods inadequate. This often leads to "a reevaluation of their entire method of teaching, which is usually very teacher centered" (Master, 1992, p. 80).

Our institution has responded directly to these serious pedagogical training needs through a series of workshops. The sessions that we have devised and /or adapted to meet these challenges could be useful in other CBI training programs. A few detailed examples follow.

Early sessions are devoted to giving faculty a realistic portrait of the student body and a preview of our interdisciplinary content-based courses. To begin their pedagogical training, new instructors read and reflect on several journal articles written by colleagues experienced with our specific content-based, active learning teaching environment (Kishie, 1997; Rehorick, 1997; Rehorick \& Rehorick, 1997; Sagliano, J., 1996; Sagliano, M., 1996a, 1996b, 1997; Stewart, 1996, 1997; Tani, 1997). These publications relate areas of particular concern in our educational context to the current literature.

We then offer a session showing a series of video portfolios compiled by various instructors illustrating particular units in their courses. Before viewing each clip, the context is made explicit by the facilitators. These portfolios provide snapshots of the general student population at specific times in their studies, offering a sampling of students exhibiting a wide range of proficiency levels in performing integrated projects and classroom tasks. While presenting the videos, facilitators involve faculty in a series of active and cooperative learning tasks so that they will be exposed to the type of class- 
room procedures, dynamics, and instruction that are desired and practiced at the college.

In order to demonstrate the practical side of CBI more fully, we compile a collection of course materials designed by many of our instructors. This materials display is assembled in one large room with completed work in every aspect of content-based course design available for browsing. In this self-paced session, new faculty can discuss their questions and concerns at length with more experienced colleagues and learn valuable lessons in constructing course syllabi, course texts, unit plans, worksheets, and assessment instruments for various content-based tasks. They can also individually examine completed student assignments and watch videorecordings of classroom activities.

To make the most effective use of discipline-specific content for language instruction, the appropriateness and choice of content materials, modes of delivery, and tasks must be determined and constantly assessed. For example, the selection of teaching materials at MIC will depend on a careful consideration of the cultural, educational, and linguistic background of classes entirely composed of second-language learners. Language and content specialists must create integrated materials that are effective in teaching simultaneously content and language. To meet the different learning styles of Japanese students at MIC, input is provided in diverse ways through readings (texts, handouts), other visual materials (computer sources, OHP transparencies, videos, pictures, etc.), and listening input (mini-lectures, tapes). Swain (1996) points out that, "if second language learning is more successful when learned in meaningful contexts ... we need to be doing a lot more fundamental planning about how to integrate language and content teaching" (p. 544). Teachers need to be trained for these challenges. In response to this, we actively involve new faculty directly in evaluating and reacting to actual content-based instructional materials and associated student tasks that have been used previously at our institution. Work stations are set up, with each station having different input: an audiotape, a videotape, or a reading. Small faculty groups composed of EFL and discipline specialists review the materials and activities at each station, evaluate their appropriateness and effectiveness for CBI, and finally devise ways to adapt materials and create new tasks that integrate language skills and disciplinespecific concepts. The initial groups disband and ideas are shared in new groups as participants continue to learn from each other.

\section{Training Point \#4: Socialization to Cooperative Team-Based. Relationships}

Aim: Facilitate interdisciplinary collaboration among faculty. For a variety of reasons related to the college teaching profession itself, faculty members are often hampered in implementing any novel form of instruction such as 
team-based teaching. Problems arise, for example, from the nature of the organizational structure of colleges and from the inherent preferences of teachers. One significant issue is that US institutions of higher learning often do not foster cooperative behavior among their faculty, although cooperation is obviously an essential ingredient for successful team-teaching. Johnson, Johnson, and Smith (1991) claim that "the organizational structure of colleges must change from a competitive/mass-manufacturing structure within which faculty work alone to a high performance, team-based organizational structure in which faculty work in teams" (p. 115).

The same co-authors further their argument by characterizing college professors as acting independently, working in isolation, and having no impact on what their colleagues do. Teaching settings are viewed as isolationist, and teachers as individualistic and autonomous (Hatton, 1985). As one professor puts it, "Teaching has been kept private; it is rarely talked about, and professors seldom visit each other's classes" (Smith, 1995, p. 77). Hatton (1985) quotes Hargreaves, who states that "teaching is seen as an intimate act which is most effectively and properly conducted when shrouded in privacy" (p. 230). Boice (1992) emphasizes "the collegially private activity of teaching" (p. 51). In addition, Wright (Budd \& Wright, 1992) reflects on "the experience of discovering the 'privateness' of a teacherlearner group relationship." This reflection leads him to discover "the problem of "sharing' classrooms with colleagues," and he voices his own "surprise on discovering the privacy" when he begins to share team-teaching responsibilities (p. 225).

Even though

the design, implementation, and assessment of integrated curricula can be greatly enhanced when teachers of different disciplines form interdisciplinary teams ... collaborative models currently prevalent in schools do not generally include team projects in which TESOL and mainstream teachers engage in interdisciplinary partnership for curriculum planning, structuring of programs, implementation, and evaluation. (Kaufman \& Brooks, 1996, p. 233)

The fact is that team-teaching is fraught with challenges. Many teachers are reluctant to relinquish their power in making their own decisions and instructional implementations in the classroom (Bailey, Dale, \& Squire, 1992).

Because faculty members are clearly not used to working in dynamic team-based structures, our teachers must be guided in interdisciplinary team-teaching. This learning process is ongoing throughout the academic year and necessarily involves a great deal of inservice training. Therefore, aspects of interdisciplinary cooperation presented in our preservice workshops are critical, as they form the basis for this continuous professional development. The preservice workshops listed in Appendix A incorporate 
collaborative experiences in curriculum and syllabus design, in materials development, in classroom practice, and in instructional computer use.

Of primary importance is the promotion of close professional working relationships between EFL and discipline-specific faculty. From the outset, however, we acknowledge that $\mathrm{CBI}$ and team-teaching both contain the potential for interpersonal and professional conflicts. An important step to help avoid some of the inevitable interpersonal conflicts is to have all faculty members recognize and anticipate probable areas of disagreement early, to discuss them openly, and to outline ways to solve these problems in an amenable and professional fashion.

Content-based training facilitators might consider offering, as we have, workshops that deal directly with the unavoidable challenges that arise in such programs. We create a series of scenarios based on situations that have happened in the past among our EFL and content faculties and present them to new faculty members for discussion in interdisciplinary groups. In this way faculty hear opinions from different perspectives, begin to appreciate each other's points of view, and thereby arrive at a reasonable consensus about how challenges in team-teaching can be resolved, or avoided.

One week before the end of the preservice training program, new faculty are asked to meet with an assigned teaching partner and begin course planning discussions. As a culminating activity, they are given the specific task of preparing a week's lesson plan and one activity that integrates language and content study. At the final session of this training program, new teaching partners are asked to present their co-developed team-teaching plan and one integrated classroom activity to the faculty. After all the teams present their ideas, a round-table discussion and question-and-answer session of teaching issues peculiar to our context is held.

\section{Training Point \#5: Inservice Training}

Aim: Develop faculty competence in CBI through ongoing training. A preservice orientation program is essential for successful training and development of faculty in content-based programs. However, to further professional development, a complementary inservice program is necessary. Why is this fundamental? Developing the particular knowledge base and procedural skills to work with content-based approaches such as CALLA, for instance, requires many hours of inservice training (Chamot \& O'Malley, 1994). Short (1991b) contends that professional development needs to be built into a program design to ensure that it is ongoing and that it deals with the practical matters that surface regularly. This is especially relevant for contentbased teaching situations because "continual cooperation between content and language instructors is vital throughout the period of instruction" (Brinton et al., 1989, p. 59). Researchers agree that continuity and a lengthy period 
of time are required for such complex training to be successful (Brinton et al., 1998).

A number of procedures have been developed over four years of experience in orientation at our college that other training facilitators might consider to complement a preservice program at the postsecondary level. After preservice orientation ends, teaching teams at our institution continue to work together before classes begin. During this period teams need to develop their syllabi, course materials, and projected lesson plans. A number of resources in addition to those provided during the orientation are available to new faculty members to help them develop their courses. New colleagues can find ideas in the materials produced for previous courses. They can also work intensively with experienced colleagues whenever they feel the need. In addition, once the teaching semester begins, professional orientation committee members and other faculty continue to make themselves available to new colleagues for consultation about areas of concern and open their classrooms to them. This is especially encouraged during the early weeks of classes, a time that could be disorienting and even an overwhelming adjustment for some new colleagues. Special inservice mentoring relationships can also be set up for any faculty member requesting extra assistance. On a related point, we publicize the schedule of preservice workshops widely and invite all faculty to attend them. In some cases faculty members have been recommended to attend selective workshops.

Our curriculum requires that all first- and second-year courses be taught by language and content instructor teams. To facilitate content-based teamteaching, we advise that teams meet on a weekly basis once classes begin, usually two to three times per week. Thus inservice training continues every week throughout the semester as a result of the formation and continuity of team partnerships in which discussions centering on joint lesson planning, classroom instruction, and assessment are an ongoing necessity. In addition, faculty in related disciplines meet nearly every month to discuss issues of general concern and to share teaching techniques. About once each term special workshops are designed for instructors in areas such as instructional computer use and materials development. Furthermore, while faculty members work on publications, they are encouraged to discuss their work at our monthly colloquium.

There is also a voluntary teacher development program in which everyone is encouraged to participate. Faculty members voluntarily initiate this program by inviting two colleagues of their choice to observe their teaching in one course and examine their course materials. Observers meet with the students in the course to learn about their views of the teacher's effectiveness. All discussions are purposely kept confidential by the observers. To retain the developmental qualities of the program the participants need to be willing to engage in frank discussions about their 
teaching. This information is solely for their use, and the process is kept strictly apart from the reappointment review procedure. These are some of the developing means through which our institution has sought to incorporate constant peer coaching in our program.

\section{Ongoing Issues}

Of course, feedback to our professional orientation activities and our own teaching experiences at MIC over the past four and a half years has raised several issues related to the training we have offered. First, orientation members and administrators often disagree on the amount of time, and the degree to which, new faculty should spend on building a foundation of knowledge about nonteaching and noncurricular areas such as the contents of faculty handbooks, work rules, and committee responsibilities. Perhaps a separation in orientation responsibilities is needed whereby faculty orientation facilitators concentrate on curricular themes and administrators handle personnel issues at other times. Next, some newly arrived, veteran teachers may actually be resistant to change although they express enthusiasm for the studentcentered program during the orientation session. They may engage actively in orientation activities, but once classes are in session quickly revert back to previous modes of planning and instruction. Well-established teaching habits are often so ingrained that much time and encouragement is needed for a teacher to make a change in his or her planning and teaching approach. Inservice training must somehow intervene in these instances in a sensitive and timely manner so that advice and support can be provided. Finally, new faculty are often reluctant to admit to problems that they experience with partners or to express concerns related to daily planning and instruction. For example, the power balance in some team-teaching partnerships may be difficult to maintain. Failure to resolve initial problems could bring about a breakdown in integrated instruction where a focus either on content or language could dominate classroom instruction. New faculty must be encouraged to seek advice from colleagues and to overcome their fear that initial adaptation difficulties will reflect negatively on the teacher who raises the issue.

\section{Conclusion}

The program we describe assumes that "for collaborative teaching to be effective, teachers need appropriate training and support ... [and] need adequate time to plan their programs" (Nunan, 1992, p. 7). This is true in all CBI teaching contexts. Employing content-based models "demands great amounts of staff time for training teachers" (Leaver \& Stryker, 1989). However, because most preservice teacher preparation programs in TESL have been slow to respond to the need for training in CBI, administrators at 
institutions that employ content-based approaches have little alternative except to design their own extensive training programs. In our CBI training program, we strove to meet the conditions emphasized above by Nunan (see Appendix B for a sample of faculty reactions to the 1998 training program). It is our belief that the five training points we identify in this article, and continue to develop to suit our program, can inform all CBI teacher trainers.

\section{The Authors}

Julie Sagliano, Michael Sagliano, and Timothy Stewart are assistant professors of English at Miyazaki International College in Miyazaki, Japan. Besides having several years of experience in the CBI program, they all have extensive teaching experience in EFL contexts, particularly in Japanese institutions. They have been involved for the past two to four years as facilitators in the college's annual training program for new faculty.

\section{References}

Bailey, K.M., Dale, T., \& Squire, B. (1992). Some reflections on collaborative language teaching. In D. Nunan (Ed.), Collaborative language learning and teaching (pp. 162-178). Cambridge, UK: Cambridge University Press.

Boice, R. (1992). The new faculty member: Supporting and fostering professional development. San Francisco, CA: Jossey-Bass.

Boice, R. (1995). Developing writing, then teaching, amongst new faculty. Research in Higher Education, 36, 415-456.

Bonwell, C.C., \& Eison, J.A. (1991). Active learning: Creating excitement in the classroom. ASHE-ERIC Higher Education Report No. 1. Washington, DC: George Washington University, School of Education and Human Development.

Brinton, D.M., Crandall, J., Kaufman, D., Snow, M.A., \& Stoller, F. (1998, March). Challenges of content-based instruction for teacher education. Colloquium presented at the meeting of the Thirty-second Annual Convention \& Exposition of TESOL, Seattle, WA.

Brinton, D.M., Snow, M.A., \& Wesche, M.B. (1989). Content-based second language instruction. New York: Newbury House.

Budd, R., \& Wright, T. (1992). Putting a process syllabus into practice. In D. Nunan (Ed.), Collaborative language learning and teaching (pp. 208-229). Cambridge, UK: Cambridge University Press.

Chamot, A.U., \& O'Malley, J.M. (1994). The CALLA handbook: Implementing the cognitive academic language learning approach. Reading, MA: Addison-Wesley.

Dunkin, M.J. (1990). The induction of academic staff to a university: Processes and products. Higher Education, 20, 47-66.

Fink, L.D. (1992). Orientation programs for new faculty. New Directions for Teaching and Learning, 50, 39-49.

Flowerdew, J., \& Miller, L. (1996). Lectures in a second language: Notes towards a cultural grammar. English for Specific Purposes, 15(2), 121-140.

Gomez, E.L. (1995). The integration of language and content instruction: A training program for middle school educators. Talking About TESOL, 18, 1, 7, 10.

Hatton, E. (1985). Team-teaching and teacher orientation to work: Implications for the preservice and inservice preparation of teachers. Journal of Education for Teaching, 11, 228-244.

Havita, N. (1995). The department-wide approach to improving faculty instruction in higher education: A qualitative evaluation. Research in Higher Education, 36, 377-413.

Hess, N., \& Ghawi, M. (1997). English for academic purposes: Teacher development in a demanding arena. English for Specific Purposes, 16, 15-26. 
Hones, D.F., \& Gee, M.K. (1993/1994). Flying by the seat of one's pants: An intensive teacher preparation program. TESOL Journal, 3, 8-12.

Jameson, J. (1996, March). Integrating language and content: A framework for secondary teachers. Paper presented at the meeting of the Thirtieth Annual Convention \& Exposition of TESOL, Chicago, IL.

Johns, A.M. (1997). Text, role, and context: Developing academic literacies. Cambridge, UK: Cambridge University Press.

Johnson, D.W., Johnson, R.T., \& Smith, K.A. (1991). Cooperative learning: Increasing college faculty instructional productivity. ASHE-ERIC Higher Education Report No. 4. Washington, DC: George Washington University, School of Education and Human Development.

Kaufman, D. (1997). Collaborative approaches in preparing teachers for content-based and language-enhanced settings. In M.A. Snow \& D.M. Brinton (Eds.), The content-based classroom: Perspectives on integrating language and content (pp. 175-186). New York: Longman.

Kaufman, D., \& Brooks, J.G. (1996). Interdisciplinary collaboration in teacher education: A constructivist approach. TESOL Quarterly, 30, 231-251.

Kishie, S. (1997). Learning to debate: Ingredients for the Japanese expression classroom. Comparative Culture, 3, 16-20.

Leaver, B.L., \& Stryker, S.B. (1989). Content-based instruction for foreign language classrooms. Foreign Language Annals, 22, 269-275.

Master, P. (1992). What are some considerations for teacher training in content-based instruction? CATESOL Journal, 5(1), 77-84.

Meyers, C. \& Jones, T.B. (1993). Promoting active learning: Strategies for the college classroom. San Francisco, CA: Jossey-Bass.

Nunan, D. (Ed.). (1992). Collaborative language learning and teaching. New York: Cambridge University Press.

Otsubo, H. (1995). Japan's higher education and Miyazaki International College: Problems and solutions. Comparative Culture, 1, 1-9.

Peterson, P.W. (1997). Knowledge, skills, and attitudes in teacher preparation for content-based instruction. In M.A. Snow \& D.M. Brinton (Eds.), The content-based classroom: Perspectives on integrating language and content (pp. 158-174). New York: Longman.

Rehorick, D. (1997). Principles of group formation: Adaptations for teaching in a Japanese college. Comparative Culture, 3, 4-7.

Rehorick, S., \& Rehorick D. (1997). Merging language and content through multidimensional curriculum design. Comparative Culture, 3, $24-28$.

Sagliano, J. (1996a). Focusing on debate to develop language skills in English as a foreign language (EFL) courses in college. Comparative Culture, 2, 104-114.

Sagliano, M. (1996b). Survey on professional orientation (unpublished report). Miyazaki, Japan: Miyazaki International College, Language Faculty.

Sagliano, M. (1996). Reading college social science texts: Three problem areas. Comparative Culture, 2, 74-86.

Sagliano, M. (1997). Card games: Flexible tools for active learning. Comparative Culture, 3, 12-15.

Short, D. (1991a). Content-based English language teaching: A focus on teacher training. Cross Currents, 18(2), 167-173.

Short, D. (1991b). How to integrate language and content instruction: A training manual (2nd ed.). Washington, DC: Center for Applied Linguistics.

Short, D. (1994). Expanding middle school horizons: Integrating language, culture and social studies. TESOL Quarterly, 28, 581-608.

Smith, R.A. (1995). Creating a culture of teaching through the teaching portfolio. Journal on Excellence in College Teaching, 6(1), 75-99.

Snow, M.A. (1992). What options exist for funding content-based programs? CATESOL Journal, $5(1), 157-163$. 
Snow, M.A. (1997). Teaching academic literacy skills: Discipline faculty take responsibility. In M.A. Snow \& D.M. Brinton (Eds.), The content-based classroom: Perspectives on integrating language and content (pp. 290-304). New York: Longman.

Snow, M.A., \& Brinton, D.M. (Eds.). (1997). The content-based classroom: Perspectives on integrating language and content. New York: Longman.

Snow, M.A., \& Kamhi-Stein, L.D. (1996). Teaching academic literacy skills: Strategies for content faculty. Los Angeles, CA: California State University, Los Angeles and the Fund for the Improvement of Postsecondary Education.

Stewart, T. (1996). Organizing and teaching course content in fully integrated language and content instruction. Comparative Culture, 2, 1-17.

Stewart, T. (1997). Wanting to talk: Discussion building in a Japanese college classroom. Comparative Culture, 3, 8-11.

Swain, M. (1996). Integrating language and content in immersion classrooms: Research perspectives. Canadian Modern Language Review, 52, 529-548.

Tani, M. (1997). Teaching archaeology to first-year students: Reflections and suggestions, Comparative Culture, 3, 21-23.

Tricamo, J., \& Snow, M.A. (Directors). (1995). Improving university instruction for language minority students: Strategies from project LEAP [Video]. Los Angeles, CA: Fund for the Improvement of Postsecondary Education (Producer). (Available from Project LEAP, Library South, Palmer Wing, Room 1062A, California State University, Los Angeles, Los Angeles, California, 90032). 


\begin{tabular}{lclc}
\hline 2February (session \#1) & 3 February & 4 February (session \#2) & 5 February (session \#3) \\
$9: 00-9: 30$ & & $9: 30-12: 30$ & $1: 00-4: 00$ \\
Introductions & $X$ & Address by the president & Students of MIC \\
Schedule & & Curriculum overview & $X$ \\
$9: 30-11: 00$ & Administrative offices and & \\
Resource tour of campus & functions
\end{tabular}

$$
\text { 1:00-3:00 }
$$

Computer session \#2*

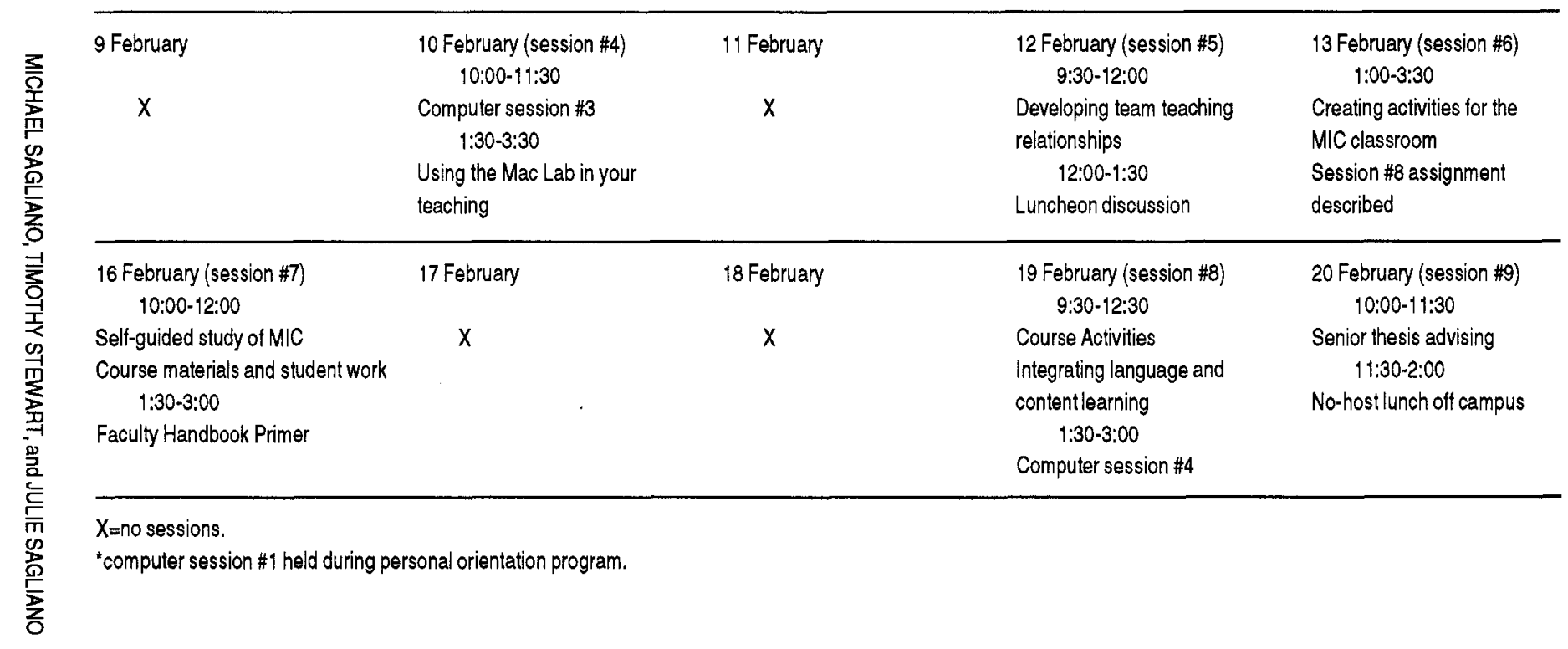




\section{Appendix B: Selected Comments on Professional Orientation 1998*}

\section{Strengths}

The Professional Orientation was well conceived, effectively executed, and, as far as I know, highly appreciated by the new faculty.

The orientation's strength lies in that it was very informative and straight forward in presenting the college environment and what it means for individual faculty members.

The biggest strength, as I saw it, was the use of cooperative learning activities during the orientation itself. It's said people teach as they've been taught-hopefully this had some impact.

All of these sessions were useful because they were practical: team teaching, creating activities for the MIC classroom, and week one course planning. They might be expanded.

The hands-on "learn about the activity by doing it yourself" approach has the advantage of indirectly introducing classroom techniques.

Generally speaking, it was a very positive and good learning experience.

Having lunches together was good. I appreciate the chance to relax and talk to colleagues informally.

\section{Areas for Improvement}

I think that the pedagogical theories of "content-based, active learning" as well as other EFL concepts might have been more openly discussed at the beginning to provide everyone with more of a foundation in and respect of the concepts.'

I didn't like the sharp division between personal and professional orientation. The main problem, as I saw it, was that after we had become familiar with the personal orientation committee members, we were suddenly newcomers all over again.

It seems that the orientation was a bit too long but, we got a clear picture of MIC.

Some sessions / presentations were too long and lost the crispness.

It would have been helpful if there were more video of different teachers both teaching and interacting with the students.

You might want to group things according to practical, theoretical, and administrative more clearly.

*representative selections from follow-up survey of 9 March 1998. 